\title{
O FUNDEF e a eficiência na provisão municipal de ensino fundamental
}

\author{
Marco Túlio Aniceto França ${ }^{a *}$, Flávio de Oliveira Gonçalves ${ }^{\text {b*** }}$ \\ aPontifícia Universidade Católica do Rio Grande do Sul, Porto Alegre, RS, Brasil \\ bUniversidade Federal do Paraná, Curitiba, PR, Brasil \\ *marco.franca@pucrs.br \\ **f.goncalves@ufpr.br
}

\begin{abstract}
Resumo
0 artigo estima a relação entre a implantação do FUNDEF (Fundo de Manutenção e de Desenvolvimento do Ensino Fundamental e de Valorização do Magistério) e a eficiência na gestão municipal do ensino no ano de 2007. Para o cálculo da eficiência, primeiro empregou-se o modelo SBM (slacks basedmeasure) com as características discricionárias. posteriormente, por meio de um modelo Tobit, controlamos o efeito das variáveis não discricionárias. A estimação da relação entre o FUNDEF e a eficiência foi através de modelos de seleção em observáveis. Os dados foram oriundos do Censo Escolar, Prova Brasil Finbra (Finanças do Brasil). Os resultados mostram uma melhoria de eficiência a partir de oito anos de adoção do programa e os estímulos corretos ao processo de descentralização. 0 trabalho conclui que a criação de uma estrutura de gestão municipal do ensino fundamental eficiente demanda tempo e abre boas perspectivas para os resultados esperados com o FUNDEB (Fundo de Manutenção e Desenvolvimento da Educação Básica e de Valorização dos Profissionais da Educação).
\end{abstract}

Palavras-chave

Eficiência. Microeconometria. Educação. Política pública.

\section{Introdução}

Os sistemas de ensino possuem características próprias que o tornam peculiares em relação às políticas destinadas à área. 0 conjunto de políticas direcionadas à reforma educacional basicamente dividem-se em dois tipos: foco em acréscimos de qualidade e eficiência escolar ou são direcionadas para a expansão do número de matrículas. 0 Brasil, assim como outros países da América Latina, optou pela segunda alternativa e realizou políticas descentralizantes no setor. A principal delas foi a criação do FUNDEF (Fundo de Manutenção e Desenvolvimento do Ensino Fundamental e de Valorização do Magistério), que é um fundo de âmbito estadual, porém, formado com recursos de todos os entes federados (Municípios, Estados e União), e a divisão ocorre de acordo com o número de matriculados no ensino fundamental sob a sua dependência administrativa. Outros trabalhos que abordam o FUNDEF são Mendes (2001), Rodriguez (2001) e Oliveira \& Teixeira (2009).
0 principal efeito da reforma foi redistributivo, além de ter incentivado a municipalização. Esse processo dentro de cada um dos Estados decorreu na transferência de recursos das escolas estaduais (relativamente mais ricas) para as municipais (relativamente mais pobres). Ademais, se após a transferência de recursos o gasto por estudante no Estado ficasse abaixo do mínimo estabelecido pela União, este ente cobriria a diferença. Dessa forma, pode-se afirmar que a medida beneficiou tanto os Estados quanto os Municípios. Em relação ao primeiro, houve um aumento nos níveis de equidade dentro dos Estados e, para o segundo, incentivou a expansão das suas redes de ensino.

0 objetivo do presente trabalho é analisar a relação entre o FUNDEF e a eficiência (alocação dos recursos) do sistema municipal de ensino em 2007, isto é, ano seguinte à substituição do FUNDEF pelo FUNDEB (Fundo de Manutenção e Desenvolvimento da Educação Básica e de Valorização dos Profissionais 
da Educação). Na estratégia de identificação, os efeitos do FUNDEF serão mensurados por intermédio da criação de novas escolas e/ou transferência das unidades escolares da esfera estadual para a municipal. Ademais, será considerado na análise o volume líquido de recursos recebidos pelos Municípios.

Embora o fundo não condicione os repasses de recursos a aumentos de eficácia e eficiência dos sistemas públicos de ensino, o consequente processo de municipalização incentivado pela adesão ao FUNDEF, supostamente, traria ganhos nessas questões em virtude do aumento da transparência no uso dos recursos, proximidade com a população e facilidade na responsabilização dos gestores da política pública. 0 FUNDEF proveu alguns incentivos econômicos para a concretização das políticas municipalizantes formuladas desde a Constituição de 1988 e reforçada com a LDB (Lei de Diretrizes e Bases da Educação Nacional) de 1996, do Estatuto da Criança e do Adolescente (ECA), da Emenda Constitucional 14/1996, além de um conjunto de normas infraconstitucionais e resoluções do Conselho Nacional de Educação (CNE).

A criação do FUNDEB em 2007, em substituição ao FUNDEF, teve como principal modificação a incorporação do ensino infantil e médio na distribuição dos recursos, reduzindo, portanto, o caráter competitivo por recursos existentes entre os níveis decorrentes do FUNDEF. Nesse arcabouço, um maior número de Municípios e níveis de ensino passaria a ser contemplado com recursos vis-à-vis o FUNDEF. Todavia, ambos os fundos não foram criados com o objetivo de reduzir os desequilíbrios de recursos entre os Estados e, ademais, permanece não considerando as questões relacionadas à eficiência e a eficácia da aplicação dos recursos.

É importante destacar que, embora seja provável que o FUNDEF tenha estimulado o aumento no número de estudantes matriculados no ensino fundamental, uma vez que os repasses são de acordo com o tamanho do alunado, todavia, não é possível dizer que o aumento no número de estudantes, sem o aumento da rede, poderá aumentar a eficiência. Embora esse arcabouço possa mostrar-se benéfico devido aos ganhos de escala, a gestão municipal pode mostrar-se não suficientemente preparada para esta nova situação, decorrente, por exemplo, da incapacidade do corpo técnico ou falta de accountability. Por outro lado, os efeitos da municipalização sobre a eficiência podem levar tempo para serem captados pelo processo de aprendizado que deve ocorrer dentro da administração da educação municipal.

As variáveis que compõem o IDEB (taxa de aprovação, desempenho em língua Portuguesa e Matemática) foram empregadas como produtos no cálculo da eficiência municipal. A eficiência será calculada por meio da DEA (Data Envelopment Analysis) e, posteriormente, descontaremos a influência do "ambiente", que é representada pelas características não discricionárias (cor autodeclarada pelo estudante e nível socioeconômico médio municipal) e que podem afetar significativamente a eficiência.

Os resultados mostram que os Municípios responderam aos incentivos dados pelo FUNDEF ao expandirem suas redes de ensino por meio da criação e/ou transferência de escolas da esfera estadual. Dessa forma, o fundo estimulou a descentralização do ensino na esperança de melhorar o gerenciamento dos recursos. Entretanto, não houve elevação de eficiência e, em diversos anos, observou-se um decréscimo. 0 resultado pode decorrer de falhas nos órgãos de fiscalização criados pelo FUNDEF na responsabilização dos gestores da política, isto é, a accountability não estimulou maior eficiência. Além disso, pode ser consequência da não existência de um condicionante para o recebimento dos recursos que esteja ligado a uma administração eficiente. Os resultados em termos de eficiência são sentidos apenas oito anos após a adoção do programa, caracterizando um processo de aprendizado da gestão municipal de educação. Esta relação de longo prazo foi observada apenas na transferência de escolas, o que nos leva à hipótese de que o processo de aprendizado para a expansão do sistema (criação de novas escolas) possa tomar mais tempo que aquele da transferência administrativa entre esferas do governo.

0 trabalho está dividido em quatro seções, além desta introdução. Na seção 2, faremos um breve histórico do FUNDEF. Na seção 3 será mostrada a estratégia empírica para a estimação da eficiência. A seção 4 diz respeito à fonte dos dados. Na seção 5 serão delineados os resultados. Finalmente, faremos as considerações finais.

\section{0 FUNDEF}

A Constituição promulgada no ano de 1988 tornou os Municípios um ente federado com discricionariedade na formulação de políticas públicas, assim como os Estados e a União. Dentro desse novo arcabouço, à União foi delegado o financiamento do ensino superior, das escolas técnicas federais e a garantia da transferência de recursos para os demais entes federados, de forma a assegurar um gasto mínimo por aluno. Aos Estados, coube a oferta do ensino médio e, concomitantemente, auxiliar os Municípios na oferta do ensino fundamental. Os Municípios se tornaram os principais provedores de vagas desse nivel de ensino e, recentemente, houve a incorporação do ensino infantil. 
As reformas descentralizantes resultaram em acréscimos no montante de recursos para os Estados e Municípios. A distribuição da receita de impostos entre os níveis de governo (Federal, Estadual e Municipal) na década de 1960 era de 59,44\%, 34,01\% e 6,55\%, respectivamente. Contudo, em 1997, o governo federal passou a receber $56,4 \%$, os Estados 27,5\% e os Municípios 16,1\%. Assim, os Municípios e os Estados seriam os principais "ganhadores" e "perdedores", respectivamente, com as reformas. Todavia, a vinculação de recursos na ordem de 20\% a $25 \%$ para gastos em educação, como determinava a Constituição, não era cumprida de fato e, assim, os mais diversos artifícios contábeis eram empregados.

Apesar de as reformas supracitadas mostrarem-se importantes, a principal delas decorreu da criação do FUNDEF (criado em 1996 e que entrou em vigor em 1998, com duração prevista de 10 anos) por intermédio da Emenda Constitucional 14/96 e da Lei 9324/96 que, além de garantir um gasto mínimo por aluno da rede pública (independente da dependência administrativa) por parte do governo federal, estabeleceu que Estados e Municípios vinculassem 20\% das receitas para educação.

No embate político, uma vez que as reformas tramitaram em apenas duas semanas, as principais objeções vieram dos Estados, que perderam poderes de discricionariedade na condução das políticas de ensino e afirmavam que as séries finais do ensino fundamental (quintas a oitavas séries) e o ensino médio teriam o volume de recursos reduzidos. Ao nível municipal, as jurisdições mais pobres apontavam que seriam obrigadas a prover vagas para um setor que, em parte, não tinham interesse. As ações do governo federal visando à neutralização do poder de negociação dos Estados vieram por intermédio do apoio de dois sindicatos importantes em nível estadual: CONSED (Conselho Nacional de Secretários da Educação) e a UNDIME (União Nacional dos Dirigentes Municipais de Educação), que fizeram oposição aos governadores dos Estados para a aprovação do FUNDEF.

0 fundo é de natureza contábil, com atuação em âmbito estadual, e composto por 15\% das principais receitas de impostos [FPE (Fundo de Participação dos Estados), FPM (Fundo de Participação dos Municípios), IPI-Exportação (Imposto sobre Produtos Industrializados para Exportação), ICMS (Imposto sobre Circulação de Mercadorias e Serviços) e desoneração das exportações (lei Kandir)] de Estados e Municípios. Todos os entes federados devem contribuir para o fundo, contudo, os recursos são repartidos de acordo com o número de matrículas no ensino fundamental (regular e especial) levantados no Censo Escolar (Instituto Nacional de Estudos e Pesquisas Educacionais Anísio Teixeira, 2007a) do ano anterior, e segundo o montante previsto para o FUNDEF (Brasil, 2011a) no ano corrente. É importante ressaltar que, os valores referentes ao ensino especial são ligeiramente superiores ao regular. A União transfere recursos para o fundo se o valor mínimo por estudante no Estado mostrar-se inferior ao firmado pela União.

Embora tenha sido criado em 1996, o fundo entrou em vigor em 1998, sendo estabelecido um valor mínimo de 315 reais por aluno - e no último ano, 2006, o valor era de 682,60 reais. Nesse arcabouço, em oito Estados a União necessitou transferir recursos para atingir o patamar mínimo. Cabe destacar que, os valores mínimos por aluno diferem entre os Estados, devido à impossibilidade da transferência de recursos entre eles. Contudo, há uma equalização entre os Municípios de um mesmo Estado.

Os Municípios que não possuíam escolas de ensino fundamental sob sua gerência não tiveram direito aos repasses provenientes do fundo. Esse aspecto incentivou a municipalização do ensino fundamental, uma vez que o aumento no número de matrículas incorreria em acréscimos de recursos. A adoção de políticas descentralizantes (a municipalização é uma delas) visa aproximar a população dos responsáveis pela elaboração das políticas públicas. 0 resultado seria um maior monitoramento e uma menor assimetria de informação entre esses agentes, consequentemente, as necessidades locais seriam mais facilmente atendidas, e os gestores poderiam ser mais facilmente responsabilizados (Oates, 1972).

Nesse sentido, concomitantemente ao fundo, criaram-se os Conselhos de Acompanhamento e Controle Social (CACS/FUNDEF) com a participação de membros da sociedade civil, cujo objetivo é o acompanhamento e controle da distribuição dos recursos, além de supervisionar a realização do Censo Escolar. 0 conselho seria o meio de controlar e responsabilizar os gestores pela má gerência dos recursos, além de aglutinar a sociedade em torno de um objetivo comum. Todavia, não sabemos até que ponto esses conselhos teriam discricionariedade na aplicação de medidas punitivas quando os recursos são mal geridos.

Assim, verificaremos se as modificações devido à adoção do fundo trouxeram acréscimos de eficiência para os Municípios. É importante destacar que, de acordo com Tanzi (1996), nos Municípios prevaleceriam características relacionadas ao clientelismo em comparação a esferas superiores. Portanto, a municipalização conduziria a uma baixa eficiência devido à menor capacidade técnica e de gerenciamento por parte dos gestores locais (Galiani et al., 2008). Bardhan \& Mookherjee (2005) vão além, ao afirmarem que políticas descentralizantes podem levar à "captura" dos recursos pela elite local. De acordo com esse cenário, 
os segmentos que não estão no poder simplesmente não teriam suas necessidades atendidas.

\section{A estratégia empírica}

\subsection{Análise da eficiência}

A relação entre o FUNDEF e a eficiência dos sistemas públicos de ensino será analisada em três etapas. Primeiramente, estimar-se-á por intermédio da análise de envelopamento de dados (DEA), porém, com o emprego de um modelo aditivo (SBM - Slacks Based Measure) proposto por Tone (2001), a eficiência no uso dos insumos e produtos por parte do gestor da educação municipal. 0 uso dessa medida, em vez das medidas radiais tradicionais - CCR (Charnes et al., 1978) ou BCC (Banker et al., 1984) - se deve pela fácil interpretação econômica: a unidade de medida tanto para os insumos quanto para os produtos ser invariante mede o grau de ineficiência presente nos insumos e produtos e não necessita definir a priori o tipo de orientação - insumo ou produto -, uma vez que no cálculo da eficiência ambas as orientações são consideradas simultaneamente.

Os Municípios, $j$, denominados de DMUs, utilizam a FPE (função de produção educacional) para transformar $m$ insumos $x_{i j}=\left(x_{1 \mathrm{j}}+x_{2 \mathrm{j}}+\ldots+x_{m j}\right) \in R_{+}^{M}$ em $s$ produtos $x_{k j}=\left(y_{1 \mathrm{j}}+y_{2 \mathrm{j}}+\ldots+y_{s j}\right) \in R_{+}^{S}$. A tecnologia utilizada é homogênea e o conjunto de possibilidades de produção representa todas as combinações possíveis de insumos e produtos. É importante destacar que, de acordo com Tone (2001), a condição de não negatividade dos insumos e produtos pode ser relaxada, uma vez que valores negativos podem ser substituídos por pequenos valores positivos. A medida tem amplitude entre 0 e 1 e, quanto mais próximo de 1, mais eficiente é o Município.

Alguns trabalhos que empregaram a metodologia DEA para o Brasil e tiveram as escolas como unidade de análise, são citados por Delgado \& Machado (2007), que mensuram a eficiência das escolas públicas estaduais de Minas Gerais. Gasparini \& Ramos (2003) mensuram a eficiência e a efetividade do ensino médio ofertado pelos Estados. Zoghbi et al. (2009) utilizam os dados do SAEB-2003 para mensurar a eficiência e o desempenho dos gastos em educação dos Estados em relação aos ensinos fundamental e médio. É importante destacar que os trabalhos supracitados não controlam os efeitos decorrentes dos insumos não discricionários e que, porventura, afetam os índices de eficiência.

Assim, descontaremos do cálculo do SBM as influências relativas às características do corpo discente (etnia autodeclarada pelo estudante e nível socioeconômico médio municipal que são representados pelo capital humano e econômico dos pais). De acordo com Ruggiero (1996), as variáveis de ambiente, isto é, que não estão sob o controle direto do Município e que são denominadas não discricionárias, podem apresentar efeitos relevantes no resultado final. Os Municípios cuja proporção de estudantes de escolas públicas possuem pais com níveis elevados de capital humano, provavelmente, terão desempenhos superiores em testes de proficiência em relação aos Municípios cuja proporção mostra-se inferior. Assim, será empregado o modelo Tobit a fim de controlar o efeito dos fatores não discricionários devido à característica da variável dependente ser censurada em 1. Cabe destacar que, a nova medida de eficiência será dada pelo resíduo dessa regressão, procedimento semelhante ao de Ray (1991).

0 regredido será a estimativa calculada no DEA-SBM, cujos valores são censurados em 1, e os regressores serão as variáveis não discricionárias, a saber: o nível socioeconômico médio do Município e o percentual de estudantes que se autodeclararam pardos, negros, índios ou amarelos. De acordo com a metodologia de Ray (1991), os resíduos da regressão correspondem à eficiência da gestão educacional dos Municípios. No entanto, Ray (2004) destaca que é preciso aplicar um método de correção sobre os resíduos, $\varepsilon_{j}$, uma vez que eles podem ser positivos ou negativos, a fim de se obter uma medida de eficiência gerencial. Para isso, aplica-se o método de correção de Greene, cujo procedimento visa subtrair de todos os resíduos o maior valor positivo. Como os valores do resíduo tornam-se negativos por default, a aplicação do antilog sobre o resultado passará a refletir a eficiência gerencial municipal e não estarão relacionados a qualquer variável não discricionária.

Finalmente, o cálculo de como o FUNDEF influencia a eficiência gerencial dos Municípios será por intermédio de modelos de seleção em observáveis, como o propensity score matching (PSM). 0 método consiste em encontrar um grupo de comparação que seja o mais similar possível em termos de propensity score, gerado a partir das características observáveis. Devido à não existência de um grupo de controle que surja naturalmente de um experimento aleatório, uma vez que a divisão de recursos no FUNDEF está condicionada ao número de estudantes matriculados no ensino fundamental, procura-se elaborar um contrafactual ou um grupo de controle que seja o mais similar possível em termos de características observáveis.

É importante destacar que a construção do contrafactual decorre, de acordo com Caliendo \& Kopeining (2005), da impossibilidade de se observar, ao mesmo tempo sobre o Município, dois resultados 
de uma determinada política, logo, superando o problema relacionado ao viés de seleção.

Assim, na estratégia de identificação haveria quatro resultados potenciais, com o primeiro a respeito dos Municipios que sempre tiveram escolas municipais de ensino fundamental antes da vigência do FUNDEF e permaneceram na gerência dessas escolas. 0 segundo caso corresponde aos Municípios que não tinham escolas sob a sua dependência administrativa antes do fundo e, a partir de então, passaram a gerenciá-las. Ou seja, novas escolas foram criadas ou houve a transferência de escolas da esfera estadual para a municipal. 0 caso seguinte seria o contrário do anterior: os Municípios teriam escolas sob sua dependência administrativa antes do FUNDEF, e essas passaram para a tutela do Estado após o início da vigência do fundo. Por fim, há Municípios que permanecem sem ter escolas sob a sua gerência antes e depois do início da vigência do fundo.

Assim, serão feitos dois exercícios: o primeiro comparar os Municípios que expandiram as suas redes de ensino devido ao FUNDEF (tratamento 1) via a criação de novas escolas, tendo como grupo controle aqueles Municípios que não expandiram a sua rede de escolas. 0 segundo exercício será comparar os Municípios que expandiram sua rede apenas com a transferência de escolas da esfera estadual (tratamento 2) com o grupo de Municípios composto por aqueles que não expandiram a sua rede no período. Embora as análises ocorram em separado e para cada um dos anos, os grupos de controle não sofreram modificação no decorrer do tempo, permanecendo os Municípios que não expandiram a rede até 2007.

0 método se divide em duas etapas: a primeira diz respeito à estimação do propensity score, $P(X)$, que segundo Becker \& Ichino (2002) pode ser realizada por meio de qualquer modelo de probabilidade padrão. Em geral, empregam-se modelos logit/probit na estimação, a fim de se obter a probabilidade de participação, dadas as suas características observáveis. No passo seguinte, estima-se o efeito do FUNDEF sobre a eficiência por intermédio de diferença de médias e empregando o método do vizinho mais próximo e de kernel. Enquanto o primeiro possui a vantagem do não descarte de observações tratadas, é importante ressaltar que os propensity score empregados podem não possuir valores muito próximos. Em relação ao kernel, as unidades tratadas serão pareadas com as de controle apenas se o valor do propensity score estiver dentro de uma vizinhança previamente definida de propensity score das unidades de tratamento. Ou seja, esta característica contornaria o problema observado no pareamento pelo vizinho mais próximo.

\section{Fonte dos dados}

As informações referentes às escolas e estudantes serão extraídas do Censo Escolar e da Prova Brasil (Instituto Nacional de Estudos e Pesquisas Educacionais Anísio Teixeira, 2007a, b), respectivamente, ambos para 2007. 0 Censo Escolar possui as informações da educação básica e consiste em um levantamento de dados realizado em âmbito nacional e em todos os anos, por intermédio da colaboração das secretarias municipais e estaduais de educação.

A Prova Brasil é um exame universal e aplicado somente nas escolas urbanas do sistema público de ensino. As séries de referência submetidas ao exame são as quartas (quinto ano) e oitavas séries (nono ano) do ensino fundamental. A metodologia de avaliação utiliza as matrizes de referência que permitem aos alunos responderem a diferentes testes, porém, possuindo itens comuns. 0 desempenho do estudante é mensurado de acordo com a teoria de resposta ao item, comumente chamada de TRI. Esta variável é o indicador das habilidades e competências dos estudantes, ou seja, o indicador de qualidade na sua formação. Os resultados da Prova Brasil vêm acompanhados de informações a respeito das características familiares dos estudantes. Os resultados variam de 0 a 500 e propõem-se a avaliar as habilidades e conhecimentos dos alunos.

$\mathrm{Na}$ análise serão utilizadas as informações referentes às quartas séries (quinto ano) do ensino fundamental, uma vez que muitos Municipios incorporaram esse nível de ensino sob a sua administração, assim, tendo o direito aos repasses de recursos oriundos do FUNDEF. Os produtos da função de produção educacional serão os desempenhos municipais nos exames da Prova Brasil em Matemática e em Língua portuguesa. Podemos observar que, de acordo com a Tabela 1A (Anexo A), o desempenho médio dos Municípios em Matemática e em Língua Portuguesa foi de 187,56 e 168,87 pontos, respectivamente. Em ambos os casos, a média encontra-se abaixo do valor considerado ideal, que é de 250 pontos para esse nível de ensino. Além desses, serão considerados a taxa de aprovação municipal na série de referência do exame e o número de escolas a fim de levar em consideração o tamanho da rede de ensino que está sob a gestão do município.

As variáveis escolares e que estariam sob o controle do gestor foram construídas por meio da análise fatorial, técnica multivariada cujo objetivo é descrever as variáveis originais por meio de um número menor de fatores e que está relacionada ao conjunto original da variável por intermédio de um modelo linear. Os fatores são uma dimensão latente 
que se manifesta de forma redundante em algumas variáveis originais (Johnson \& Wichern, 1998).

Dessa forma, três variáveis latentes foram elaboradas e representam a infraestrutura física escolar, como a conservação de itens: portas, janelas, banheiros, cozinha, entrada do prédio, paredes externas, pátio, corredores e salas de aula. Por meio da mesma técnica, elaborou-se a infraestrutura de equipamentos (televisão, mimeógrafo, videocassete/DVD e aparelho de som) e de informática (computadores, impressoras, retroprojetor, projetor de slides e xerox). Os programas governamentais em nivel federal, estadual e municipal, existentes nas escolas dos Municípios, mostram o grau de intervenção no ensino, oriundo de outras esferas governamentais. A razão entre o número de salas de aulas e de escolas do Município, assim como a razão professor/aluno, foram inseridas, uma vez que são outros indicadores da qualidade da infraestrutura educacional e que também são empregadas na literatura. Além disso, consideramos o percentual de professores com ensino superior para considerar a qualidade do corpo docente.

As variáveis de ambiente, também denominadas não discricionárias, serão oriundas das características dos estudantes da esfera municipal que participaram do exame. Para a elaboração do nível socioeconômico, também foi empregada a metodologia da análise fatorial, técnica já usada para a construção das infraestruturas escolares. As variáveis utilizadas foram o número de televisores, rádios, videocassete/DVD, geladeira, carros, banheiros, quartos para dormir, número de livros em casa e o grau de escolaridade dos pais. Assim, essa variável latente foi identificada como o nível socioeconômico médio das escolas municipais e será empregada para a mensuração do peer effects local. Ademais, é importante ressaltar que medir o nível de renda dessa forma calcula a renda residual da família, após os gastos com a educação dos filhos. Por fim, destaca-se que variáveis binárias também foram utilizadas e se referem à etnia autodeclarada pelo estudante (pardo, preto, amarelo e indígena). As médias e os desvios-padrão dessas variáveis encontram-se na Tabela $2 \mathrm{~A}$.

As variáveis municipais serão empregadas no pareamento entre os Municípios que pertencem aos grupos de tratamento (criaram ou receberam escolas durante o período de 1998 a 2006) e controle (Municípios que até 2007 não haviam criado escolas ou recebido escolas por meio de transferência da rede estadual) na mensuração da relação do FUNDEF. As variáveis adicionais são o grau de desigualdade de renda que é mensurado pelo índice de Gini para o ano de 2000 (Instituto Brasileiro de Geografia e Estatística, 2001), o logaritmo da população para o ano de 2007 e as variáveis políticas para 2004. As informações serão para os anos de 1998 a 2006, e compreenderão as variáveis que dizem respeito ao volume líquido de recursos do FUNDEF. Além disso, elaboraram-se variáveis binárias para representar duas situações: i) a ocorrência da criação de novas escolas municipais; ii) quando houve a transferência da responsabilidade de gerenciamento das escolas da esfera estadual para a municipal. As médias e os desvios-padrão dessas variáveis encontram-se na Tabela 3A.

Por fim, é importante destacar que a descrição das variáveis supracitadas se encontra na Tabela 1.

As informações referentes aos Municípios em relação aos recursos do fundo são oriundas do Ministério da Fazenda - STN (Secretaria do Tesouro Nacional) (Brasil, 2011a) e Ministério da Fazenda/STN/Finbra (Finanças do Brasil) (Brasil, 2011b) para os anos de 1998 a 2006. 0 índice de desigualdade será extraído do IPEA (Instituto de Pesquisa Econômica Aplicada, 2011) e utilizar-se-á como referência o ano de 2000. Assim como as variáveis empregadas no primeiro e no segundo estágio de análise, as médias e os desvios-padrão das variáveis supracitadas encontram-se no Anexo A Tabela 3A.

As variáveis políticas elaboradas para o ano de 2004 consistiram da fragmentação partidária nas câmaras municipais e o grau de competição para os cargos de prefeito e de vereador. A fragmentação é mensurada pelo índice de RAE (Rae \& Taylor, 1970) e se baseia na probabilidade de dois vereadores, escolhidos aleatoriamente, pertencerem a partidos diferentes em uma dada eleição. 0 índice é calculado pela divisão do índice de Fracionalização $\left(1-\left(\Sigma \mathrm{pe}^{2}\right)\right)$ pelo índice de Fracionalização Máxima ( $(\mathrm{n}-1) / \mathrm{n}(\mathrm{N}-1))$, onde: $\mathrm{pe}^{2}$ é o percentual de cadeiras ocupadas por cada partido, $\mathrm{N}$ = número de cadeiras e $\mathrm{n}=$ número de partidos. 0 índice varia entre 0 (zero) e 1 (um) e pode nos dar uma medida da existência de dominância por parte de um dos partidos, seja este de situação ou de oposição. 0 grau de competição mensura 0 quão confortável as elites locais se encontrariam nos cargos eletivos.

A literatura reconhece o problema de causalidade reversa entre os níveis de democracia e variáveis educacionais. Alguns exemplos de trabalhos que estimam a relação entre as variáveis educacionais, participação política e cidadania são Dee (2004), Milligan et al. (2004) e Acemoglu et al. (2005). De acordo com Acemoglu et al. (2005), a endogeneidade entre democracia e educação resulta de os investimentos educacionais por parte das autoridades eleitas poderem estar fortemente ligados às suas preferências. A relação entre democracia e educação decorre do fato de que uma elevação nos anos de estudo aumenta a demanda por democracia (Tavares \& Wacziarg, 2001). Para contornar tal problema na estimação do efeito direto das variáveis políticas sobre as variáveis educacionais, optou-se pela construção de uma variável latente que fosse independente da variável 
Tabela 1. Variáveis empregadas na análise.

\begin{tabular}{|c|c|}
\hline \multicolumn{2}{|r|}{ Insumos ( $1^{\circ}$ estágio). } \\
\hline Infrafísica & Infraestrutura física escolar no Município. \\
\hline Infra_equip & Infraestrutura de equipamentos escolares no Município. \\
\hline Prog_Fed. & $\%$ de escolas com programas federais. \\
\hline Prog_Estad. & $\%$ de escolas com programas estaduais. \\
\hline Prog_Mun. & \% de escolas com programas municipais. \\
\hline Supprof & \% de professores com ensino superior no Município. \\
\hline Prof_aluno & Razão professor aluno no Município. \\
\hline \multicolumn{2}{|r|}{ Produtos ( $1^{\circ}$ estágio). } \\
\hline Nota_Mat & Desempenho médio municipal em Matemática. \\
\hline Nota_Port. & Desempenho médio municipal em Língua Portuguesa. \\
\hline Tx_aprov & Taxa de aprovação média do Município \\
\hline N_escolas & Número de escolas do Município \\
\hline \multicolumn{2}{|r|}{ Variáveis não discricionárias ( $2^{\circ}$ estágio). } \\
\hline Pardo & $\%$ de estudantes que se autodeclararam pardos. \\
\hline Preto & $\%$ de estudantes que se autodeclararam pretos. \\
\hline Amarelo & $\%$ estudantes que se autodeclararam amarelos. \\
\hline Índio & $\%$ de estudantes que se autodeclararam descendentes de indígenas; $0=$ outros. \\
\hline Nsemedio & Nível socioeconômico médio dos estudantes da rede municipal. \\
\hline \multicolumn{2}{|r|}{ Variáveis de caracteristicas municipais ( $3^{\circ}$ estágio). } \\
\hline GIN12000 & Grau de desigualdade de renda mensurado pelo índice de Gini para 2000. \\
\hline LNPOP07 & Logaritmo da população em 2007 \\
\hline VAR_POL & Variáveis políticas para o ano de 2004. \\
\hline LNFUNDXX & Logaritmo dos recursos do FUNDEF entre os anos de 1998 e 2006. \\
\hline ESCRIAXX & 1 = Municípios que criaram escolas municipais no ano $X X$, sendo que $X X=1998, . ., 2006 ; 0=$ outros. \\
\hline ESTRNSXX & 1 = Municipios que receberam escolas da esfera estadual no ano $X X$, sendo que $X X=1998, . ., 2006 ; 0=$ outros. \\
\hline GANXX & 1 =Municípios que foram recebedores líquidos do FUNDEF no ano $X X$, sendo que $X X=1998, . ., 2006.0=$ outros. \\
\hline
\end{tabular}

Fonte: Elaborado pelos autores. Extraídos do INEP/Prova Brasil 2007/entre os anos de 1998 e 2007 (Instituto Nacional de Estudos e Pesquisas Educacionais Anísio Teixeira, 2007b). Ministério da Fazenda - STN (Brasil, 2011a) e Ministério da Fazenda/STN/Finbra (Brasil, 2011b) entre os anos de 1998 e 2006. TSE 2004 (Brasil, 2011c).

educacional. Esta construção foi realizada por meio de análise fatorial na qual às variáveis políticas foi adicionada a variável educacional. A análise sugere duas componentes, na qual a primeira mostra grande carga fatorial (56\% da variância) à variável educacional, enquanto, na segunda, as variáveis políticas têm grande peso fatorial (25\%). Estas componentes são, por construção, ortogonais, o que contornaria o problema relativo à endogeneidade.

A fim de detectar o comportamento dos Municípios após a entrada em vigor do fundo, elaboramos duas variáveis binárias para cada um dos anos (entre 1998 e 2006) relacionados à criação de novas escolas ou à transferência de escolas da esfera estadual para a municipal. Para isso, utilizamos os dados do número de escolas do Censo Escolar e foi considerado que uma escola nova foi criada, se não tiver reduzido o número de escolas estaduais no Município. Caso contrário, considerou-se a ocorrência de uma transferência administrativa, isto é, a escola deixou de ser estadual e passou a ser municipal, uma vez que, concomitantemente, houve a redução no número de escolas estaduais.

Na Figura 1 abaixo, podemos observar a evolução entre os anos de 1998 e 2006 de quatro variáveis: o logaritmo natural do volume de recursos do FUNDEF,
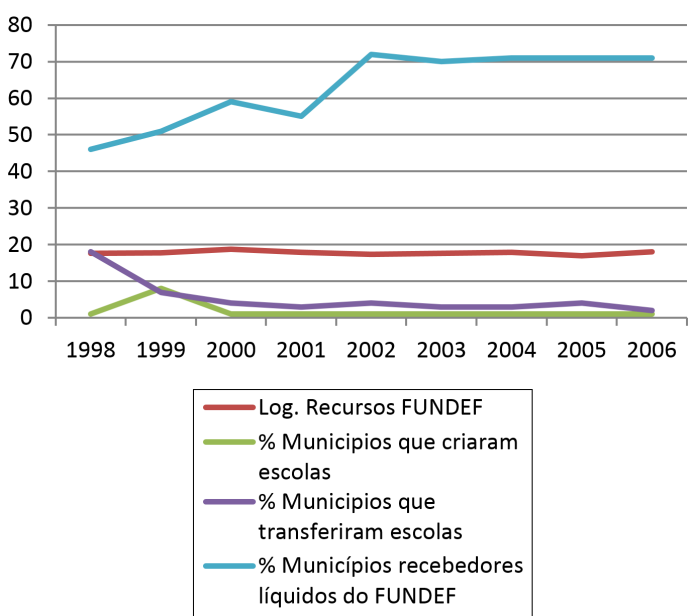

Figura 1. Evolução das variáveis. Fonte: Censo escolar (Instituto Nacional de Estudos e Pesquisas Educacionais Anísio Teixeira, 2007a) e Ministério da Fazenda - STN (Brasil, 2011a) ambos para 1998-2006. Elaborado pelos autores.

o percentual de Municípios que tornaram recebedores líquidos de recursos do fundo, o percentual de Municípios que criaram escolas municipais e o percentual de Municípios que receberam escolas da esfera estadual. 
As estatísticas descritivas relacionadas ao percentual de Municípios que se tornaram recebedores líquidos no decorrer dos anos de vigência do fundo se encontram na Tabela 4A.

De acordo com a Figura 1, as estimativas mostram que o percentual médio de escolas criadas foi maior no ano de 1999, que é o ano seguinte ao início do fundo. Nos demais anos, o percentual permaneceu constante. Contudo, observa-se que no ano de 1998, em média, 18\% dos Municípios receberam escolas oriundas da esfera estadual. 0 percentual manteve-se, em média, em 4\%, mostrando-se superior aos valores relativos à criação de unidades educacionais. $\mathrm{Na}$ média, observamos que, o volume de recursos do FUNDEF permaneceu constante no decorrer do período, todavia, houve crescimento paulatino no número de Municípios que se tornaram recebedores líquidos do fundo.

Ainda de acordo com a mesma figura, podemos verificar que o percentual de Municípios que são, na média, recebedores líquidos de recursos do fundo aumenta de $46 \%$ para $71 \%$ no decorrer dos anos, com um total de 3.697 Municípios. Isto é, os Municípios se adaptam à regra para obter acréscimos de recursos. Em termos regionais, verifica-se que a maioria dos Municípios das regiões Norte e Nordeste foram recebedores líquidos do fundo. É importante destacar que, os Estados que recebem complementação da União pertencem a essas regiões. Logo, os Estados cujos Municípios já administravam suas escolas beneficiaram-se com o fundo. Contudo, em relação aos devedores líquidos, encontram-se 1.862 Municípios, sendo em sua maioria nas regiões Sul e Centro-oeste. Verifica-se uma baixa correlação entre o valor líquido recebido e o grau de desigualdade de renda medido pelo Gini, embora o sinal seja positivo. E, como esperado, o valor líquido recebido tem alta correlação com o número de escolas e de matriculados.

0 crescimento das matrículas no período correspondeu a $38 \%$ na média, e observa-se que a política predominante foi de aumento do número estudantes dentro das escolas e não de aumento da rede. 0 resultado é esperado, porque a regra estabelece que o repasse dos recursos do FUNDEF seja condicionado, exclusivamente, ao número de estudantes no ensino fundamental.

Na próxima seção, serão delineados os resultados relativos à influência do FUNDEF no âmbito da eficiência para as quartas séries do ensino fundamental em 2007.

\section{O FUNDEF eleva a eficiência da gestão educacional?}

A análise verificará o efeito do fundo sobre a eficiência na gestão educacional municipal. Assim, primeiramente, estimaremos a eficiência dos Municípios por intermédio de um modelo SBM (Slacks Based Measure), pois não é necessário definir o tipo de orientação - insumo ou produto -, além de ser invariante em torno das unidades de medida para os insumos e os produtos.

Os insumos empregados na função de produção educacional e que estão sob o controle do gestor são o percentual de professores com ensino superior, a presença de programas federais, estaduais e municipais, a infraestrutura física e de equipamentos escolares, além da razão professor/aluno e sala/aluno. Os produtos são as variáveis que compõem o IDEB (notas em Matemática, língua Portuguesa e a taxa de aprovação), além do número de escolas.

A estimação ocorreu para 4.438 Municípios, sendo que 185 se mostraram eficientes sob esta ótica. Todavia, para a mensuração da eficiência gerencial, é necessário controlar pelas variáveis não discricionárias. Estas variáveis podem afetar os níveis de eficiência, embora não esteja sob o controle direto do gestor. A estratégia de estimação será o uso de um modelo Tobit, uma vez que os valores estão censurados em 1 e as características inseridas na análise correspondem aos atributos estudantis, como a cor autodeclarada e o nível socioeconômico médio. Na Tabela 2, apresentamos os resultados do modelo.

Os resultados da regressão mostram que praticamente todas as variáveis são estatisticamente significantes a $1 \%$, logo, sendo uma evidência de que as características não discricionárias afetam a eficiência e todas agem no sentido de reduzi-la. Podemos verificar, de acordo com a Tabela 5A, as estimativas para as capitais, antes de descontar pelos não discricionários. A capital mais eficiente é Campo Grande, seguida por Florianópolis e Vitória. Na parte inferior da tabela, as capitais menos eficientes são do Rio de Janeiro e do Maranhão.

Após a estimação com as variáveis não discricionárias, aplicou-se o método de correção de Greene, cujo procedimento visa subtrair de todos os resíduos, o maior valor positivo. Como os valores do resíduo tornam-se negativos por default, a aplicação do

Tabela 2. Resultado do Modelo Tobit com a inclusão de variáveis não discricionárias.

\begin{tabular}{lccc}
\hline \multicolumn{1}{c}{ Variáveis } & Coeficiente & Erro padrão & Valor $\mathbf{p}$ \\
\hline Nsemedio & $-0,032$ & 0,012 & 0,005 \\
Pardo & $-0,094$ & 0,029 & 0,001 \\
Preto & $-0,350$ & 0,059 & 0,000 \\
Amarelo & $-0,240$ & 0,142 & 0,091 \\
Índio & $-0,295$ & 0,104 & 0,005 \\
Constante & 0,199 & 0,016 & 0,000 \\
Sigma & 0,24 & 0,02 & \\
\hline
\end{tabular}

Fonte: Elaborado pelos autores. 275 observações foram censuradas em 1. 
antilog sobre o resultado passará a refletir, de acordo com Ray (2004), a eficiência da gestão municipal, e não estará relacionado a qualquer variável não discricionária.

Os resultados sobre a eficiência, após descontar os efeitos dos fatores não discricionários, são apresentados na Tabela 3. Na ótica dos Estados, verifica-se que, aqueles Municípios que pertencem à região Sul, na média, são mais eficientes. 0 Município de referência (eficiência igual a 1) encontra-se nessa região. Os Estados menos eficientes, na média, foram a Bahia e o Rio de Janeiro.

$\mathrm{Na}$ ótica das capitais, a mais eficiente torna-se Curitiba, seguida por Florianópolis e Fortaleza. Enquanto Florianópolis não muda de posição, há uma mudança substancial no ranking, pois Curitiba estava em $16^{\circ}$ e Fortaleza em $22^{\circ}$, respectivamente, antes de levar em consideração essas características. Na parte inferior da tabela, Salvador e Vitória foram as capitais com menores níveis de eficiência, após o desconto pelas não discricionárias cujas posições anteriormente eram de $11^{\circ}$ e $3^{\circ}$, respectivamente, no ranking. Os resultados podem ser observados na Tabela 5A.

De acordo com a Tabela 4, observamos que existe uma baixa correlação entre os recursos oriundos do fundo para cada um dos anos e o grau de eficiência estimado em 2007. Além disso, o sinal da correlação mostra-se sempre negativo, isto é, quanto maior o repasse, menos eficiente mostra-se o Município, mesmo após controlarmos pelas variáveis não discricionárias.

A etapa seguinte será estimar a relação do FUNDEF e a eficiência municipal, após controlar pelas características observáveis. A metodologia utilizada será a de propensity score matching, e as características municipais incluídas na estimação do modelo probit/logit foram as dummies de estado, o logaritmo da população, o índice de Gini que mede a desigualdade de renda (Instituto Brasileiro de Geografia e Estatística, 2001), o logaritmo relativo aos recursos do fundo e a variável política. Espera-se que as variáveis empregadas na estimação sejam ortogonais à entrada no FUNDEF e que não existam características observáveis importantes, caso contrário, não se pode afirmar que a entrada ou não no fundo seja aleatória.

Os indicadores de tratamento serão dados pela ocorrência de criação de novas escolas ou de transferência de escolas da esfera estadual para a municipal. 0 grupo de controle é composto pelos Municípios que não expandiram as suas escolas via criação ou transferência. Ou seja, um Município que fazia parte do grupo de tratamento em 2002 devido à criação de escolas poderá tornar-se grupo controle em 2004, caso nenhuma das ações supracitadas tenham sido executadas. Assim, para cada um dos anos em análise, utilizou-se uma especificação diferente para compatibilizar temporalmente as variáveis. Ademais, empregou a opção de suporte comum para que sejam somente comparadas as observações que pertençam ao tratamento e ao controle e que se encontram dentro dessa região. Os resultados se encontram nas Tabelas 5 e 6.

De acordo com os resultados da Tabela 5, a relação do FUNDEF e a eficiência, após empregar o método de pareamento pelo vizinho mais próximo e por kernel, mostra poucas diferenças, contudo, elas são interessantes. É importante destacar que o método de pareamento por kernel evita o uso de valores para o propensity score que sejam muito diferentes.

Em geral, os Municípios que expandiram as suas redes por meio da criação de novas escolas não revelam acréscimos de eficiência. Os resultados mostraram sinais negativos e foram significantes para os anos de 2000, 2001 e 2006. Apesar de o recebimento dos recursos não se mostrar condicionado à elevação da

Tabela 3. Eficiência média dos Estados brasileiros após controlar pelas características não discricionárias.

\begin{tabular}{|c|c|c|c|c|c|}
\hline Estados & $\mathrm{N}$ & Média & Estados & $\mathrm{N}$ & Média \\
\hline$A C$ & 20 & 0,79 & $\mathrm{~PB}$ & 186 & 0,82 \\
\hline $\mathrm{AL}$ & 88 & 0,78 & PE & 172 & 0,81 \\
\hline AM & 47 & 0,78 & $\mathrm{Pl}$ & 194 & 0,80 \\
\hline $\mathrm{AP}$ & 11 & 0,76 & PR & 363 & 0,84 \\
\hline BA & 388 & 0,75 & RJ & 87 & 0,75 \\
\hline CE & 179 & 0,81 & $\mathrm{RN}$ & 141 & 0,81 \\
\hline ES & 71 & 0,79 & RO & 39 & 0,80 \\
\hline GO & 187 & 0,81 & $\mathrm{RR}$ & 8 & 0,78 \\
\hline MA & 200 & 0,79 & RS & 279 & 0,83 \\
\hline MG & 619 & 0,79 & SC & 204 & 0,85 \\
\hline MS & 63 & 0,81 & SE & 65 & 0,79 \\
\hline MT & 110 & 0,79 & SP & 506 & 0,82 \\
\hline PA & 128 & 0,79 & TO & 95 & 0,79 \\
\hline
\end{tabular}

Fonte: Elaborado pelos autores. 
eficiência, os resultados revelam algumas evidências de que a estratégia dos Municípios para o aumento dos recursos não veio acompanhada de melhorias na gestão do ensino.

Todavia, os resultados da Tabela 6 mostram resultados ambíguos, pois os Municípios que receberam escolas em anos específicos apresentaram acréscimos

Tabela 4. Correlação entre a eficiência e o logaritmo dos recursos do FUNDEF.

\begin{tabular}{lc}
\hline Variáveis & Eficiência \\
\hline Infund98 & $-0,05$ \\
Infund99 & $-0,07$ \\
Infund00 & $-0,08$ \\
Infund01 & $-0,11$ \\
Infund02 & $-0,19$ \\
Infund03 & $-0,17$ \\
Infund04 & $-0,18$ \\
Infund05 & $-0,16$ \\
Infund06 & $-0,20$ \\
\hline
\end{tabular}

Fonte: Elaborado pelos autores. de eficiência, se considerada a metodologia do vizinho mais próximo. Nesse caso, haveria um efeito de longo prazo no que tange aos acréscimos de eficiência, observado entre o ano seguinte à entrada em vigor do FUNDEF e o início do FUNDEB, 1998 e 2007. Ademais, resultado semelhante também é verificado para o ano 2000. Todavia, essa eficiência deixa de ser estatisticamente significante em Municípios que aderiram ao fundo em anos posteriores. Do lado oposto, ao empregarmos kernel como meio de pareamento, os resultados mostram sinais negativos no que se refere à eficiência, embora a maioria não seja estatisticamente significante, à exceção do observado para 2001. De acordo com Dehejia \& Wahba (2002), é preferivel o pareamento pelo vizinho mais próximo vis-à-vis ao de kernel, devido ao maior viés que este último apresenta.

De acordo com o pareamento pelo vizinho mais próximo, a descentralização estimulada pelo FUNDEF conduziu a maior eficiência no longo prazo, resultado

Tabela 5. Estimação da relação entre o FUNDEF e eficiência utilizando pareamento por propensity score pelo vizinho mais próximo e por kernel sobre a eficiência para os Municípios que criaram escolas: 1998-2006.

\begin{tabular}{|c|c|c|c|c|c|c|}
\hline Anos & Tratamento & Controle & $\begin{array}{c}\text { ATT (Average } \\
\text { treatment effect): } \\
\text { Efeito do tratamento } \\
\text { sobre o tratado pelo } \\
\text { método do vizinho } \\
\text { mais próximo. }\end{array}$ & Tratamento & Controle & $\begin{array}{c}\text { ATT (Average } \\
\text { treatment effect): } \\
\text { Efeito do tratamento } \\
\text { sobre o tratado pelo } \\
\text { método de Kernel }\end{array}$ \\
\hline 1998 & 45 & 31 & $-0,005$ & 45 & 1111 & $-0,005$ \\
\hline 1999 & 353 & 229 & 0,000 & 353 & 2836 & $-0,002$ \\
\hline 2000 & 56 & 36 & $-0,020^{*}$ & 56 & 1303 & $-0,02^{* *}$ \\
\hline 2001 & 37 & 29 & $-0,017^{*}$ & 37 & 1330 & $-0,017^{* *}$ \\
\hline 2002 & 46 & 32 & 0,008 & 46 & 779 & 0,001 \\
\hline 2003 & 36 & 20 & $-0,013$ & 36 & 895 & $-0,007$ \\
\hline 2004 & 31 & 25 & 0,000 & 31 & 1094 & $-0,005$ \\
\hline 2005 & 30 & 25 & $-0,001$ & 30 & 1144 & $-0,006$ \\
\hline 2006 & 27 & 24 & $-0,023^{* *}$ & 27 & 1790 & $-0,019^{* * *}$ \\
\hline
\end{tabular}

Fonte: Elaborado pelos autores. **1\% e *10\% de significância

Tabela 6. Estimação da relação do FUNDEF e eficiência utilizando pareamento por propensity score pelo vizinho mais próximo e por kernel sobre a eficiência para os Municípios que receberam escolas da esfera estadual: 1998-2006.

\begin{tabular}{|c|c|c|c|c|c|c|}
\hline Anos & Tratamento & Controle & $\begin{array}{c}\text { ATT (Average } \\
\text { treatment effect): } \\
\text { Efeito do tratamento } \\
\text { sobre o tratado pelo } \\
\text { método do vizinho } \\
\text { mais próximo. }\end{array}$ & Tratamento & Controle & $\begin{array}{c}\text { ATT (Average } \\
\text { treatment effect): } \\
\text { Efeito do tratamento } \\
\text { sobre o tratado pelo } \\
\text { método de Kernel }\end{array}$ \\
\hline 1998 & 444 & 176 & $0,012^{*}$ & 444 & 1977 & 0,003 \\
\hline 1999 & 285 & 146 & 0,001 & 285 & 1912 & $-0,002$ \\
\hline 2000 & 177 & 116 & $0,011^{* *}$ & 177 & 2338 & $-0,002$ \\
\hline 2001 & 185 & 123 & 0,000 & 185 & 2977 & $-0,007^{\text {**** }}$ \\
\hline 2002 & 155 & 96 & $-0,001$ & 155 & 1971 & $-0,002$ \\
\hline 2003 & 156 & 105 & 0,001 & 156 & 1644 & $-0,001$ \\
\hline 2004 & 158 & 101 & 0,003 & 158 & 2005 & $-0,005$ \\
\hline 2005 & 209 & 99 & 0,010 & 209 & 2512 & 0,002 \\
\hline 2006 & 112 & 72 & 0,000 & 112 & 2266 & $-0,008$ \\
\hline
\end{tabular}

Fonte: Elaborado pelos autores. ${ }^{* * *} 1 \%$ de significância, ${ }^{* *} 5 \%$ e * $10 \%$ de significância. 
interessante, uma vez que a proximidade da população com os gestores da política possa trazer resultados positivos. Todavia, não se consegue observar resultado estatisticamente significante em períodos mais curtos de implantação do programa. Os resultados sobre a eficiência da gestão local, quando o processo de descentralização ocorre por criação e transferência de escolas, sugerem que o processo de aprendizado na gestão de um sistema local de ensino leva tempo, e que este é maior quando o governo local expande sua rede através da criação de novas escolas em vez da simples transferência.

\section{Conclusão}

0 trabalho mediu a relação do FUNDEF com a eficiência da provisão municipal do ensino em 2007, ano em que o fundo foi extinto e substituído pelo FUNDEB. Além dos recursos líquidos recebidos pelos Municípios oriundos do fundo, consideramos as estratégias adotadas pelos Municípios em resposta ao FUNDEF: a criação de novas escolas ou o recebimento de escolas da esfera estadual.

A eficiência foi estimada por intermédio de uma extensão dos modelos aditivos, denominados Slacks Based Measure (SBM), em um segundo estágio a eficiência calculada é descontada da parcela que pertence às variáveis não discricionárias, ou seja, os atributos (as características familiares dos estudantes, como a cor e o nível socioeconômico) que não estão nas mãos do gestor. Assim, compararam-se os Municípios que expandiram suas redes via a criação ou o recebimento de escolas em relação aos Municípios que não expandiram e/ou criaram unidades de ensino. Em ambas as análises, as estimativas da eficiência no ano de 2007 foram realizadas com base na entrada do Município no programa em um dos anos de vigência, isto é, entre os anos de 1998 e 2006.

Os resultados mostram que o fundo estimulou a descentralização do ensino na esperança de melhorar o gerenciamento dos recursos. lsso pode ser observado pelo aumento no número de escolas municipais, tanto por meio da criação quanto do recebimento de unidades escolares da esfera municipal. Além disso, o percentual de Municípios que tornaram recebedores líquidos do fundo cresceu no decorrer dos anos, sendo os principais beneficiados os Estados da região Norte e Nordeste que também recebem complementação dos recursos da União, uma vez que os valores doados pelos Municípios ficam abaixo de um valor mínimo.

Quando o processo de descentralização deu-se pela criação de novas escolas, não foram observados ganhos de eficiência no período inicial. Entretanto, verifica-se um acréscimo de eficiência a partir de oito anos de implantação do programa sobre escolas transferidas. Esse resultado pode ser decorrente da baixa capacidade técnica local no gerenciamento de uma maior rede e o processo de aprendizado de sua gestão.

Em relação à expansão da rede via incorporação de escolas estaduais, mostrou-se positiva no curto prazo, embora o efeito foi sendo perdido no decorrer do período. Os resultados podem decorrer de um enforcement ineficiente em relação à má gestão dos recursos do FUNDEF ou ser consequência da inexistência da obrigatoriedade de uma condicionante para uma administração eficiente no que tange aos recebimentos dos recursos.

\section{Referências}

Acemoglu, D., Johnson, S., Robinson, J. A., \& Yared, P. (2005). From education to democracy? The American Economic Review, 95(2), 44-49. http://dx.doi.org/10.1257/000282805774669916.

Banker, R. D., Charnes, A., \& Cooper, W. W. (1984). Some models for estimating technical and scale inefficiencies in data envelopment analysis. Management Science, 30(9), 1370-1382. http://dx.doi.org/10.1287/mnsc.30.9.1078.

Bardhan, P., \& Mookherjee, D. (2005). Decentralizing antipoverty program delivery in developing countries. Journal of Public Economics, 89(4), 675-704. http://dx.doi.org/10.1016/j. jpubeco.2003.01.001.

Becker, S. 0., \& Ichino, A. (2002). Estimation of average treatment effects based on propensity score. Stata Journal, 2(4), 358-377. Recuperado em 9 de setembro de 2011, de http://www.sobecker.de/pscore.html

Brasil. Ministério da Fazenda. Secretaria do Tesouro Nacional. (2011a). Execução orçamentária dos Estados 1998-2006. Brasília: Tesouro Nacional. Recuperado em 25 de outubro de 2011, de http://www.stn.fazenda.gov.br/web/stn/ contas-anuais

Brasil. Ministério da Fazenda. Secretaria do Tesouro Nacional. (2011b). Finbra - Finanças do Brasil: 1998-2006. Brasília: Tesouro Nacional. Recuperado em 25 de outubro de 2011, de http://www.stn.fazenda.gov.br/web/stn/carrosselprefeituras-01

Brasil. Tribunal Superior Eleitoral. (2011c). Eleições. Brasília: Tribunal Superior Eleitoral. Recuperado em 1 de novembro de 2011, de http://www.tse.jus.br/eleicoes/eleicoes-anteriores/ eleicoes-anteriores

Caliendo, M., \& Kopeining, S. (2005). Some practical guidance for the implementation of propensity score matching. IZA Discussion Papers, 1588, 1-32.

Charnes, A., Cooper, W. W., \& Rhodes, E. (1978). Measuring the efficiency of decision making units. European Journal of Operational Research, 2(6), 429-444. http://dx.doi. org/10.1016/0377-2217(78)90138-8.

Dee, T. (2004). Are there civic returns to education? Journal of Public Economics, 88(9-10), 1697-1720. http://dx.doi. org/10.1016/j.jpubeco.2003.11.002.

Dehejia, R. H., \& Wahba, S. (2002). Propensity score matching methods for nonexperimental causal studies. The Review of Economics and Statistics, 84(1), 151-161. http://dx.doi. org/10.1162/003465302317331982. 
Delgado, V. M. S., \& Machado, A. F. (2007). Eficiência das escolas públicas estaduais de Minas Gerais. Pesquisa e Planejamento Economico, 37, 427-464.

Galiani, S., Gertler, P., \& Schargrodsky, E. (2008). School decentralization: helping the good get better, but leaving the poor behind. Journal of Public Economics, 92(10-11), 2106-2120. http://dx.doi.org/10.1016/j.jpubeco.2008.05.004.

Gasparini, C. E., \& Ramos, F. S. (2003). Efetividade e Eficiência no Ensino Médio Brasileiro. Economia Aplicada, 7(2), 389-411.

Instituto Brasileiro de Geografia e Estatística. (2001). Censo Demográfico 2000 - Resultados do Universo. Rio de Janeiro: IBGE.

Instituto de Pesquisa Econômica Aplicada. (2011). Ipeadata: Dados sociais. Brasília: IPEA. Recuperado em 23 de outubro de 2011, de http://www.ipeadata.gov.br

Instituto Nacional de Estudos e Pesquisas Educacionais Anísio Teixeira. (2007a). Censo Escolar. Brasília: INEP. Recuperado em 17 de outubro de 2011, de http://portal.inep.gov.br/ basica-censo

Instituto Nacional de Estudos e Pesquisas Educacionais Anísio Teixeira. (2007b). Prova Brasil. Brasília: INEP. Recuperado em 17 de outubro de 2011, de http://portal.inep.gov.br/ web/saeb/aneb-e-anresc

Johnson, R., \& Wichern, D. (1998). Applied multivariate statistical analysis (4. ed.). New Jersey: Prentice Hall.

Mendes, M. (2001). Descentralização do ensino fundamental: avaliação dos resultados do FUNDEF. Revista Planejamento e Políticas Públicas, 24, 27-51.

Milligan, K., Moretti, E., \& Oreopoulos, P. (2004). Does education improve citizenship? Evidence from the U.S. and the U.K. Journal of Public Economics, 88(9-10), 1667-1695. http:// dx.doi.org/10.1016/j.jpubeco.2003.10.005.

Oates, W. E. (1972). Fiscal federalism. New York: Harcourt Brace Javanovich.

Oliveira, R. F., \& Teixeira, B. B. (2009). Do FUNDEF ao FUNDEB: a qualidade ainda fora de pauta. Vertentes, 33, 36-47.

Rae, D., \& Taylor, M. (1970). The analysis of political cleavages. New Haven: Yale University Press.
Ray, S. C. (1991). Resource use efficiency in public schools: a study of Connecticut data. Management Science, 37(12), 1620-1628. http://dx.doi.org/10.1287/mnsc.37.12.1620.

Ray, S. C. (2004). Data envelopment analysis: theory and techniques for economics and operations research (376 p.). Cambridge: Cambridge University Press. http://dx.doi. org/10.1017/CB09780511606731.

Rodriguez, V. (2001). Financiamento da educação e políticas públicas: o FUNDEF e a política de descentralização. Cadernos Cedes, 21(55), 42-57. http://dx.doi.org/10.1590/ S0101-32622001000300004.

Ruggiero, J. (1996). On the measurement of technical efficiency in the public sector. European Journal of Operational Research, 90(3), 553-565. http://dx.doi.org/10.1016/03772217(94)00346-7.

Tanzi, V. (1996). Fiscal federalism and decentralization: a review of some efficiency and macroeconomic aspects. In M. Bruno \& B. Pleskovic (Eds.), Annual World Bank Conference on Development Economics 1995 (pp. 295315). Washington: World Bank.

Tavares, J., \& Wacziarg, R. (2001). How democracy affects growth. European Economic Review, 45(8), 1341-1378. http://dx.doi.org/10.1016/S0014-2921(00)00093-3.

Tone, K. (2001). A slacks-based measure of efficiency in data envelopment analysis. European Journal of Operational Research, 130(3), 498-509. http://dx.doi.org/10.1016/ S0377-2217(99)00407-5.

Zoghbi, A. C. P., Matos, E. H. C., Rocha, F. F., \& Arvate, P. R. (2009). Mensurando o desempenho e a eficiência dos gastos estaduais em educação fundamental e média. Estudos Economicos, 39(4), 785-809. http://dx.doi.org/10.1590/ S0101-41612009000400004.

\section{Agradecimentos}

Os autores agradecem à CAPES, ao CNPq e ao BNDES pelo apoio financeiro à pesquisa.

\title{
FUNDEF and the efficiency of local provisions in basic education services
}

\begin{abstract}
This paper presents an estimation of the relationship between FUNDEF and the efficiency of the Municipal Education Management in 2007. We took two steps to determine the efficiency. In the first step, we used Slack Based Measure models with discretionary variables. In the next step, we used Tobit models to control the effects of the non-discretionary characteristics. The methodology used relates FUNDEF and the efficiency measure through selection models based on observable characteristics. The datasets used were Censo Escolar, Prova Brasil and Finbra. The results indicate an increase in the levels of efficiency after eight years of FUNDEF implementation. This result indicates that the improvement of an efficient local educational structure takes time and provides good perspectives on the results of FUNDEB.
\end{abstract}

\section{Keywords}

Efficiency. Microeconometric. Education. Public policy. 
Anexo A. Lista de tabelas com as estatísticas descritivas das variáveis empregadas na análise e ranking de eficiência do ensino fundamental para capitais brasileiras antes e após controlar pelas características não discricionárias.

Tabela 1A. Insumos e produtos discricionários municipais.

\begin{tabular}{|c|c|c|c|}
\hline \multicolumn{4}{|c|}{ Insumos } \\
\hline Variáveis & Descrição & Média & Desvio-padrão \\
\hline Infrafisica & Infraestrutura física escolar no Município. & 3,67 & 1,52 \\
\hline Infra_equip & Infraestrutura de equipamentos escolares no Município. & 2,37 & 1,72 \\
\hline Prog_Fed. & 1 = a presença de programas federais; $0=$ outros. & 4,44 & 15,26 \\
\hline Prog_Estad. & $1=$ a presença de programas estaduais; $0=$ outros. & 0,11 & 0,22 \\
\hline Prog_Mun. & 1 = a presença de programas municipais; $0=$ outros. & 3,73 & 14,67 \\
\hline Supprof & Percentual de professores com ensino superior no Município. & 0,54 & 0,30 \\
\hline Prof_aluno & Razão professor aluno no Município. & 0,04 & 0,01 \\
\hline \multicolumn{4}{|c|}{ Produtos } \\
\hline Variáveis & Descrição & Média & Desvio-padrão \\
\hline Nota_Mat & Desempenho médio municipal em Matemática. & 187,56 & 20,06 \\
\hline Nota_Port. & Desempenho médio municipal em Língua Portuguesa. & 168,87 & 17,41 \\
\hline Tx_aprov & Taxa de aprovação média do Município & 84,19 & 10,34 \\
\hline N_escolas & Número de escolas do Município & 22,03 & 33,35 \\
\hline
\end{tabular}

Tabela 2A. Variáveis não discricionárias.

\begin{tabular}{llcc}
\multicolumn{1}{c}{ Variáveis } & \multicolumn{1}{c}{ Descrição } & Média & Desvio-padrão \\
\hline Pardo & 1 = estudantes que se autodeclararam pardos; $0=$ outros. & 0,47 & 0,15 \\
Preto & 1 = estudantes que se autodeclararam pretos; $0=$ outros. & 0,10 & 0,07 \\
Amarelo & 1 = estudantes que se autodeclararam amarelos; $0=$ outros. & 0,03 & 0,03 \\
Indio & 1 = estudantes que se autodeclararam descendentes de indígenas; $0=$ outros. & 0,04 & 0,04 \\
Nsemedio & Nível socioeconômico médio municipal. & $-0,23$ & 0,38 \\
\hline
\end{tabular}

Fonte: Elaborado pelos autores. Extraídos do INEP/Prova Brasil 2007 (Instituto Nacional de Estudos e Pesquisas Educacionais Anísio Teixeira, 2007b).

Tabela 3A. Variáveis municipais.

\begin{tabular}{|c|c|c|c|}
\hline Variáveis & Descrição & Média & Desvio- Padrão \\
\hline GIN12000 & Grau de desigualdade de renda mensurado pelo índice de Gini para 2000. & 0,56 & 0,06 \\
\hline LNPOP07 & Logaritmo da população em 2007 & 9,38 & 1,14 \\
\hline VAR_POL & Variáveis políticas para o ano de 2004. & $-0,04$ & 0,44 \\
\hline LNFUND98 & Logaritmo dos recursos do FUNDEF ano 1998. & 17,58 & 0,05 \\
\hline LNFUND99 & Logaritmo dos recursos do FUNDEF ano 1999. & 17,74 & 0,61 \\
\hline LNFUNDO0 & Logaritmo dos recursos do FUNDEF ano 2000. & 18,71 & 0,55 \\
\hline LNFUND01 & Logaritmo dos recursos do FUNDEF ano 2001. & 17,92 & 0,06 \\
\hline LNFUND02 & Logaritmo dos recursos do FUNDEF ano 2002. & 17,35 & 0,31 \\
\hline LNFUND03 & Logaritmo dos recursos do FUNDEF ano 2003. & 17,70 & 0,31 \\
\hline LNFUND04 & Logaritmo dos recursos do FUNDEF ano 2004. & 17,87 & 0,06 \\
\hline LNFUND05 & Logaritmo dos recursos do FUNDEF ano 2005. & 17,01 & 0,15 \\
\hline LNFUND06 & Logaritmo dos recursos do FUNDEF ano 2006. & 18,07 & 0,31 \\
\hline ESCRIA98 & $1=$ Municípios que criaram escolas municipais em 1998; 0=outros. & 0,01 & 0,11 \\
\hline ESCRIA99 & 1 = Municípios que criaram escolas municipais em 1999; 0=outros. & 0,08 & 0,27 \\
\hline ESCRIAOO & 1 = Municípios que criaram escolas municipais em 2000; $0=$ outros. & 0,01 & 0,10 \\
\hline ESCRIA01 & 1 = Municípios que criaram escolas municipais em 2001;0=outros. & 0,01 & 0,09 \\
\hline ESCRIA02 & $1=$ Municípios que criaram escolas municipais em 2002; $0=$ outros. & 0,01 & 0,09 \\
\hline ESCRIA03 & 1 = Municípios que criaram escolas municipais em 2003; $0=$ outros. & 0,01 & 0,09 \\
\hline ESCRIA04 & $1=$ Municipios que criaram escolas municipais em 2004; $0=$ outros. & 0,01 & 0,08 \\
\hline ESCRIA05 & 1 = Municípios que criaram escolas municipais em 2005; 0=outros. & 0,01 & 0,08 \\
\hline ESCRIA06 & 1 = Municípios que criaram escolas municipais em 2006; 0=outros. & 0,01 & 0,07 \\
\hline ESTRNS98 & Municípios que receberam escolas da esfera estadual em 1998; 0=outros. & 0,18 & 0,39 \\
\hline ESTRNS99 & Municípios que receberam escolas da esfera estadual em 1999; $0=$ outros & 0,07 & 0,25 \\
\hline ESTRNSOO & Municípios que receberam escolas da esfera estadual em 2000; 0=outros. & 0,04 & 0,19 \\
\hline ESTRNS01 & Municípios que receberam escolas da esfera estadual em 2001; 0=outros. & 0,03 & 0,18 \\
\hline ESTRNSO2 & Municípios que receberam escolas da esfera estadual em 2002; 0=outros. & 0,04 & 0,19 \\
\hline ESTRNS03 & Municípios que receberam escolas da esfera estadual em 2003; 0=outros. & 0,03 & 0,17 \\
\hline ESTRNSO4 & Municípios que receberam escolas da esfera estadual em 2004; 0=outros. & 0,03 & 0,17 \\
\hline ESTRNS05 & Municípios que receberam escolas da esfera estadual em 2005; $0=$ outros & 0,04 & 0,20 \\
\hline ESTRNS06 & Municípios que receberam escolas da esfera estadual em 2006; 0=outros. & 0,02 & 0,15 \\
\hline
\end{tabular}

Fonte: Ministério da Fazenda - STN (Brasil, 2011a) e Ministério da Fazenda/STN/Finbra (Brasil, 2011b) entre os anos de 1998 e 2006. TSE (Brasil, 2011c) 2004. INEP/Censo Escolar entre os anos de 1998 e 2006 (Instituto Nacional de Estudos e Pesquisas Educacionais Anísio Teixeira, 2007a). Elaborado pelos autores. 
Tabela 4A. Percentual de Municípios que foram recebedores líquidos do FUNDEF: 1998-2006.

\begin{tabular}{clc}
\hline ANO & \multicolumn{1}{c}{ Descrição } & Média \\
\hline GAN98 & Percentual de Municípios que foram recebedores líquidos do FUNDEF em 1998. & 0,46 \\
GAN99 & Percentual de Municípios que foram recebedores líquidos do FUNDEF em 1999. & 0,51 \\
GAN00 & Percentual de Municípios que foram recebedores líquidos do FUNDEF em 2000. & 0,59 \\
GAN01 & Percentual de Municípios que foram recebedores líquidos do FUNDEF em 2001. & 0,55 \\
GAN02 & Percentual de Municípios que foram recebedores líquidos do FUNDEF em 2002. & 0,72 \\
GAN03 & Percentual de Municípios que foram recebedores líquidos do FUNDEF em 2003. & 0,70 \\
GAN04 & Percentual de Municípios que foram recebedores líquidos do FUNDEF em 2004. & 0,71 \\
GAN05 & Percentual de Municípios que foram recebedores líquidos do FUNDEF em 2005. & 0,71 \\
GAN06 & Percentual de Municípios que foram recebedores líquidos do FUNDEF em 2006. & 0,71 \\
\hline
\end{tabular}

Fonte: Ministério da Fazenda - STN (Brasil, 2011a) e Finbra (Brasil, 2011b) entre os anos de 1998 e 2006. Elaborado pelos autores.

Tabela 5A. Ranking de eficiência antes e após controlar pelas características não discricionárias.

\begin{tabular}{cccccc}
\hline Capital & Ranking DEA SBM & Ranking após Tobit & Capital & Ranking DEA SBM & Ranking após Tobit \\
\hline Curitiba & 16 & 1 & Manaus & 13 & 14 \\
Florianópolis & 2 & 2 & Recife & 17 & 15 \\
Fortaleza & 22 & 3 & Belém & 18 & 16 \\
Goiânia & 23 & 4 & Porto Alegre & 15 & 17 \\
Campo Grande & 1 & 5 & Aracaju & 19 & 18 \\
Rio Branco & 5 & 6 & Macapá & 14 & 19 \\
São Paulo & 9 & 7 & Teresina & 20 & 20 \\
João Pessoa & 7 & 8 & São Luís & 25 & 22 \\
Boa Vista & 10 & 9 & Belo Horizonte & 21 & 23 \\
Maceió & 12 & 10 & Rio de Janeiro & 26 & 24 \\
Palmas & 6 & 11 & Cuiabá & 4 & 25 \\
Natal & 24 & 12 & Vitória & 3 & 11 \\
Porto Velho & 8 & 13 & Salvador & & 26 \\
\hline
\end{tabular}

Fonte: Elaborado pelos autores. 